was turned down by the DHSS, so we do not wish to censure these companies unfairly. It is regrettable that an advance in the technique of manufacture of insulin should carry a largely preventable hazard.

JOHN M STOWERS A W LOGIE

Aberdeen Royal Infirmary, Aberdeen

\section{Treatment of dermatomyositis}

SIR,-I would like to add briefly to your expert's answer on this topic (13 March, $\mathrm{p}$ 637). The current treatment of choice for steroidresistant polymyositis and dermatomyositis is probably combined methotrexate and steroid therapy given according to the method described by Metzger $e t$ al ${ }^{1}$ whereby methotrexate is given intermittently (weekly) by the intravenous route, thus probably minimising hepatotoxicity. Methotrexate toxicity has been relatively minor and always reversible. Muscle enzyme levels are reported as becoming normal after an average interval of 10 weeks, with definite improvement in muscle strength 3-4 weeks later; however, I have personal experience of a patient requiring treatment for 6 months before the enzymes became normal.

A substantial steroid-sparing effect becomes apparent when enzymes are normal and steroids can be reduced progressively as methotrexate continues in the same dose every two weeks, then every three weeks, then once monthly. However, Professor C M Pearson cautions in a personal communication that two patients who received intravenous methotrexate in a total dose of over $2000 \mathrm{mg}$ did develop mild hepatotoxicity as evidenced by slightly altered liver function tests in both and by minimal hepatic fibrosis in one patient from whom a biopsy specimen was obtained. This apparently critical total dosage level should be borne in mind.

W F DURWARD

Institute of Neurological Sciences,

Southern General Hospital,

Glasgow

Metzger, A L, et al, Annals of Internal Medicine, 1974, 81,182

\section{Guanethidine in hypertension}

SIR,-I cannot let the paper by Dr R M Pearson and others (17 April, p 933) on combination hypotensive therapy with guanethidine and oxprenolol go without comment. I would not criticise the design of their study and if advocation of such a design were their only message I would be unmoved. What I found disturbing was their comment, "We suggest that (this combination) would be useful in the routine management of patients with high blood pressure."

I thought there were some interesting points in the patients' responses that they failed to comment upon. I wondered how the initial average lying blood pressure of $203 / 120 \mathrm{~mm}$ $\mathrm{Hg}$ was arrived at, how many readings this was based on, and over how long a control period, because the mean lying blood pressure on placebo of $174 / 109 \mathrm{~mm} \mathrm{Hg}$ must surely represent a significant fall and probably represents the true blood pressure of their group of patients. We are therefore considering a group of patients with mild hypertension. I find it a horrifying thought that in such patients guanethidine, a drug long since abandoned as first-line treatment and quite rightly so because of its side effects, should rear its head again.

On the subject of side effects I would raise two points. There is no mention of the incidence in these patients of two major side effectsnamely, failure of ejaculation and symptomatic postural hypotension. Even without these, on guanethidine alone there was a $90 \%$ incidence of side effects and on combination therapy $50^{\circ}{ }_{0}$ and this in a study of only nine patients. These figures are worrying. Ayman, ${ }^{1}$ in his critique of trials of hypotensive treatment, said, "I have given placebos to hypertensive patients and obtained $80 \%$ symptomatic relief." Hypertension is on the whole an asymptomatic condition and it would be terrible thing to reverse his observation and announce, "I have given drugs to asymptomatic patients and in $80 \%$ obtained significant side effects."

I sincerely hope our colleagues from the Postgraduate Medical School are not seriously suggesting the reintroduction of guanethidine as a routine hypotensive agent. Let us continue to promote beta-blocking agents and diuretics, singly or in combination, as first-line therapy in the management of hypertension.

WILIIAM D AIEXANDER

University Hospital of Wales,

Cardiff

Ayman, D, fournal of the American Medical Association, 1949, 141, 974

Emergency treatment of hypertensive crisis following clonidine withdrawal

SIR,-The report by Drs R A Bailey and T J Neale (17 April, p 942) of a severe hypertensive crisis following the abrupt withdrawal of clonidine therapy draws attention to what may become a common medical emergency. As the authors remark, the syndrome is accompanied by excessive release of catecholamines $^{1}$ and the hypertension is likely to be particularly severe if the patient continues to take beta-adrenergic blocking agents because peripheral vasoconstriction may then be potentiated.

The recent introduction of labetalol (AH5158A; Sch 15719W), a compound with both alpha- and beta-adrenoreceptor antagonism, has provided a rational and effective treatment for such emergencies. We have observed prompt reduction of blood pressure and heart rate following intravenous labetalol in a hypertensive crisis following clonidine withdrawal. ${ }^{2}$ We recommend the intravenous injection of $50 \mathrm{mg}$ of labetalol in such situations, the dose being repeated at 5-min intervals until the blood pressure is controlled.

A similar regimen has been found suitable also for the treatment of the hypertensive crises of phaeochromocytoma, ${ }^{2}$ although the patient should subsequently be allowed upright with caution and under supervision since postural hypotension may provoke such a massive release of catecholamines from the tumour that the adrenoreceptor blockade may be overwhelmed. Labetalol is theoretically more appropriate in the treatment of hypertensive crises of phaeochromocytoma than the longer-established combination of alphablockade with a beta-blocker such as propranolol for the same reasons as Drs Bailey and
Neale recognized in their patient. Previously, unless adequate alpha-receptor blockade was established before propranolol was introduced, the hypertension might be worsened. ${ }^{3} \mathrm{With}$ intravenous labetalol both alpha- and betareceptor blockade can be induced very rapidly and concurrently. ${ }^{2}$

\section{J J BROWN A S ROBERTSON \\ E Agabiti Rosei J I S ROBERTSON \\ A F LEVER P M TRUST}

MRC Blood Pressure Unit,

Western Infirmary,

Glasgow

${ }^{1}$ Hunyor, S N, et al, British Medical fournal, 1973, 2,

Agabiti Rosei, E, et al, British fournal of Clinical

Pharmacology. In press.
Ross, E J, et al, British Medical fournal, 1967, 1, 191.

\section{Bran tablets and diverticular disease}

SIR,-The paper by Mr I Taylor and Professor H L Duthie (24 April, p 988) shows that bran tablets are of value in diverticular disease, but omits some important points.

(1) Insufficient details of the treatments are given. What exactly were the patients told about eating a high-roughage diet (HRD) and how much bran were they told to take and how often? Merely telling them to take it "whenever possible" seems vague; how much bran did the patients on HRD actually take? Did all the patients who began by eating an HRD revert to their previous diet while taking the bran tablets in the second month of the trial ? The second treatment is described as "Normacol plus an antispasmodic" without any statement of the dose of Normacol or of the dose or kind of antispasmodic. Thirdly, although the daily dose of bran tablets is specified it is not clear how often each day the patients were told to take them.

(2) The trial was designed as a crossover experiment, but the results are reported as if each treatment had been administered to a different group of patients. The whole point of using a crossover design is to prevent the inevitably large differences between patients from obscuring the differences between treatments. Within-patient comparisons are needed between each pair of treatments and for each treatment with the preceding control value.

(3) The statement that nine patients preferred "Normacol or HRD" and 11 preferred the bran tablets cannot be interpreted. How many preferred Normacol and how many preferred HRD? To what extent were these results influenced by unpleasant effects attributed to any of the treatments?

A HERXHEIMER

Department of Pharmacology and

Therapeutics,

London Hospital Medical College,

London $\mathrm{E} 1$

** We sent a copy of this letter to Mr Taylor and Professor Duthie, whose reply is printed below.-ED, $B M F$.

SIR,-In reply to Dr Herxheimer's comments we would like to make the following points.

(1) An explanation was given to the patients of which foods were high in fibre content and a diet sheet was supplied. The patients were also told to supplement this diet with bran, which could be obtained from local 